\title{
Common Mediterranean fever (MEFV) gene mutations associated with ankylosing spondylitis in Turkish population
}

\author{
Serbulent Yigit $^{\mathrm{a}}$, Ahmet Inanir ${ }^{\mathrm{b}}$, Nevin Karakus ${ }^{\mathrm{a}, \mathrm{c}, *}$, Esra Kesici $^{\mathrm{b}}$ and Nihan Bozkurt ${ }^{\mathrm{a}}$ \\ ${ }^{a}$ Department of Medical Biology, Faculty of Medicine, Gaziosmanpasa University, Tokat, Turkey \\ ${ }^{\mathrm{b}}$ Department of Physical therapy and Rehabilitation, Faculty of Medicine, Gaziosmanpasa University, Tokat, \\ Turkey

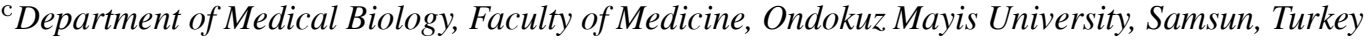

\begin{abstract}
Ankylosing spondylitis (AS) is a common inflammatory rheumatic disease. Mediterranean fever (MEFV) gene, which has already been identified as being responsible for familial Mediterranean fever (FMF), is also a suspicious gene for AS because of the clinical association of these two diseases. The aim of this study was to explore the frequency and clinical significance of MEFV gene mutations (M694V, M680I, V726A, E148Q and P369S) in a cohort of Turkish patients with AS. Genomic DNAs of 103 AS patients and 120 controls were isolated and genotyped using polymerase chain reaction (PCR) and restriction fragment length polymorphism (RFLP) methods. There was a statistically significant difference of the $M E F V$ gene mutation carrier rates between AS patients and healthy controls ( $p=0.004$, OR: 2.5, 95\% CI: 1.32-4.76). This association was also observed in allele frequencies $(p=0.005$, OR: $2.3,95 \% \mathrm{CI}: 1.27-4.2)$. A relatively higher frequency was observed for M694V mutation in AS patients than controls $(10.7 \%$ versus $4.2 \%, p=0.060)$. There were no significant differences between $M E F V$ mutation carriers and non-carriers with respect to the clinical and demographic characteristics. The results of this study suggest that $M E F V$ gene mutations are positively associated with a predisposition to develop AS.
\end{abstract}

Keywords: Ankylosing spondylitis, $M E F V$ gene, mutation, inflammatory rheumatic disease

\section{Introduction}

Ankylosing spondylitis (AS) is a common inflammatory rheumatic disease characterized by inflammation of the axial joints, peripheral oligoarthritis, and enthesitis as well as extraarticular features including acute anterior uveitis, skin lesions, and gut inflammation. The prevalence of AS was shown to be between 0.12-0.49\% in Turkey $[1,2]$. Genetic factors play an important role in the pathogenesis of AS. For nearly 40 years it has been known that HLA-B27 formed the most significant association with AS. Other than the HLA-B27, a

${ }^{*}$ Corresponding author: Dr. Nevin Karakus, Department of Medical Biology, Faculty of Medicine, Gaziosmanpasa University, 60100, Tokat, Turkey. Tel.: +90 356 2129500/7353; Fax: +90 3562133179 ; E-mail: nevinbalci@hotmail.com. number of genetic influences have been implicated in susceptibility to AS in small cohorts. One of these suspicious genes was Mediterranean fever $(M E F V)$. This gene has already been identified as being responsible for familial Mediterranean fever (FMF) [3]. Association of FMF with AS was described in several previous reports [4-10].

In persons with $M E F V$ gene mutations, it was suggested that upregulation of the inflammatory response most likely favors inflammation in general and as such predisposes $M E F V$ mutant carriers to inflammatory diseases [11]. The up-regulation of the inflammatory response in carriers of $M E F V$ mutations can also affect the severity of the accompanying chronic diseases such as rheumatoid arthritis (RA), multiple sclerosis (MS), Behcet's disease (BD), palindromic rheumatism (PR) and ulcerative colitis (UC) [12-16]. Patients with the inflammatory burden of these chronic diseases appear 
to be highly susceptible to develop a more severe disease if they also have a mutated $M E F V$.

The $M E F V$ gene is located on the short arm of chromosome 16p13.3, comprises 10 exons [17] and encodes a 781-amino acid protein called marenostrin or pyrin. Pyrin is only expressed in neutrophils and monocytes, which are the cell types involved in innate immune responses. Pyrin has a key role in the regulation of inflammasome activity and pro-interleukin- $1 \beta$ (proIL-1 $\beta$ ) processing $[18,19]$. At present, $>100$ different FMF-associated mutations of the $M E F V$ gene, which are usually located on exon 10 , have been identified. Four of these, called founder mutations (M680I, M694V, M694I, and V726A), are the most prevalent and account for most of the FMF cases worldwide [3].

It was hypothesized that, $M E F V$ mutations may change the inflammatory response to infectious and inflammatory diseases and may contribute to the development of AS. Considering that FMF is very common in Turkey and that patients with FMF can present with AS as a sole manifestation, it is important to investigate $M E F V$ mutations and impact of these mutations on AS. Therefore, we investigated whether the $M E F V$ gene might be implicated in the pathogenesis of AS. We adopted a case-control design, to compare the $M E F V$ mutation frequency between patients with AS and healthy controls, and to compare disease severity between mutation carriers and non-carriers.

\section{Materials and methods}

\subsection{Study population}

The study population comprised 103 unrelated AS patients (mean age $38.7 \pm 9.2$ years; mean disease duration $6.3 \pm 5.2$ years; 54 males, 49 females) recruited consecutively from those whom were treated and followed up in the Physical Medicine and Rehabilitation Department of Gaziosmanpasa University Research Hospital, Tokat, Turkey. All patients fulfilled the modified New York criteria for AS [20]. A total of 120 unrelated healthy subjects (mean age $40.9 \pm 13.5$ years; 53 males, 67 females) were recruited consecutively. All participants, patients and healthy controls, were of Turkish origin, from the inner Central Blacksea region of Turkey. The protocol of this study was approved by the Gaziosmanpasa University, Deanery of Medical Faculty, Medical-Surgical-Drug Research Ethics Committee (Approval no:08-GEKTIP-009), and all participants gave written informed consent before entering the study. All the participants were evaluated for the clinical findings of FMF, and none of them had symptoms or family history of FMF. The AS patients were assigned to two groups as $M E F V$ mutation carriers and non-carriers. Clinical and laboratory findings were compared between two groups.

\subsection{Analysis of $M E F V$ gene mutations}

Genomic DNA was isolated from peripheral blood lymphocytes using a commercial kit (Sigma-Aldrich, Taufkirchen, Germany), according to the manufacturer's instructions. The most frequently observed four mutations (E148Q [rs3743930; c.442G>C], M694V [rs61752717; c.2080A $>$ G], M680I, [rs28940580; c. 2040G $>$ C or c.2040G $>$ A] and V726A [rs28940579; c. $2177 \mathrm{~T}>\mathrm{C}]$ ) and an additional rare mutation (P369S [rs11466023; c. $1105 \mathrm{C}>\mathrm{T}]$ ]) in the $M E F V$ gene were screened in this study. These five mutations were detected by polymerase chain reaction (PCR) and restriction fragment length polymorphism (RFLP) analysis. PCRs of M694V, M680I, and V726A mutations were performed by using previously described protocols [21]. HinfI, HphI, and AluI restriction enzymes were used for RFLP of M694V, M680I, and V726A mutations, respectively. The sense oligonucleotide primer for E148Q was $5^{\prime}$-CCTGAAGACTCCAGACC ACCCCG- $3^{\prime}$ and the antisense primer was $5^{\prime}$-GGCC CTCCGAGGCCTTCTCTCTG- $3^{\prime \prime}$. The sense oligonucleotide primer for P369S was 5' -TCCCCGAGGCAG TTTCTGGGCACC- $3^{\prime}$ and the antisense primer was $5^{\prime}-$ TGGACCTGCTTCAGGTGGCGCTTAC-3' ${ }^{\prime}$. PCRs of E148Q and P369S mutations were performed by using previously described protocols [22]. BstNI and AluI restriction enzymes were used for RFLP of E148Q and P369S mutations, respectively. The amplified products were separated by electrophoresis on a $2 \%$ agarose gel. Ethidium bromide staining was used to detect the amplified fragments.

\subsection{Statistical analysis}

Statistical analysis was performed using the Statistical Package for the Social Sciences (SPSS 13.0) and the OpenEpi Info software package version 2.2 (www.openepi.com). Results were given as mean \pm standard deviation (S.D.). The relationships between mutation carriers and the clinical and demographics features were analyzed by using chi-square test or analysis of variance (ANOVA) statistics. Chi-square test and Fisher's exact test were used to compare categor- 
Table 1

Baseline demographics and clinical features of the 103 study patients with AS

\begin{tabular}{|c|c|c|c|c|}
\hline & Total $(n=103)$ & Carrier $(n=33)$ & Non-carrier $(n=70)$ & $P$ value \\
\hline Sex, no. male/female (male \%/female \%) & $54 / 49(52.4 / 47.6)$ & $13 / 20(39.4 / 60.6)$ & $41 / 29(58.6 / 41.4)$ & 0.069 \\
\hline Age, mean $\pm \mathrm{SD}$ (range) years & $38.7 \pm 9.2$ & $38.3 \pm 10.4$ & $38.9 \pm 8.6$ & 0.766 \\
\hline Age at disease onset, mean $\pm \mathrm{SD}$ (range) years & $32.6 \pm 9.7$ & $32.5 \pm 10.5$ & $32.7 \pm 9.3$ & 0.911 \\
\hline Disease duration, mean $\pm \mathrm{SD}$ (range) years & $6.3 \pm 5.2$ & $6.3 \pm 5.2$ & $6.2 \pm 5.2$ & 0.914 \\
\hline $\mathrm{BASDAI}$, mean $\pm \mathrm{SD}$ & $3.2 \pm 1.3$ & $3.4 \pm 1.4$ & $3.1 \pm 1.3$ & 0.246 \\
\hline Schober test, mean $\pm \mathrm{SD} \mathrm{cm}$ & $4.0 \pm 1.5$ & $4.2 \pm 1.5$ & $3.9 \pm 1.5$ & 0.343 \\
\hline Chest expansion, mean $\pm \mathrm{SD} \mathrm{cm}$ & $2.7 \pm 1.1$ & $2.7 \pm 1.2$ & $2.7 \pm 1.0$ & 0.942 \\
\hline $\mathrm{ESR}$, mean $\pm \mathrm{SD} \mathrm{mm} /$ hour & $18.3 \pm 13.6$ & $20.6 \pm 16.2$ & $17.2 \pm 12.1$ & 0.234 \\
\hline HLA-B27 status, no. (\%) & $76(73.8)$ & $27(81.8)$ & $49(70.0)$ & 0.203 \\
\hline Family history of AS, n (\%) & $18(17.5)$ & $5(15.2)$ & $13(18.6)$ & 0.670 \\
\hline Syndesmophtes, n (\%) & $26(25.2)$ & $8(24.2)$ & $18(25.7)$ & 0.873 \\
\hline Ocular involvement, $\mathrm{n}(\%)$ & $15(14.6)$ & $7(21.2)$ & $8(11.4)$ & 0.189 \\
\hline Hip involvement, n (\%) & $39(37.6)$ & $16(48.5)$ & $23(32.9)$ & 0.127 \\
\hline Cardiac involvement, n (\%) & $4(3.9)$ & $3(9.1)$ & $1(1.4)$ & 0.060 \\
\hline Articular pain, n (\%) & $73(70.9)$ & $24(72.7)$ & $49(70.0)$ & 0.776 \\
\hline Cervical pain, n (\%) & 15 (14.6) & $4(12.1)$ & $11(15.7)$ & 0.630 \\
\hline Sakroiliitis, n (\%) & $81(78.6)$ & $27(81.8)$ & $54(77.1)$ & 0.589 \\
\hline Oral aphthous ulcers, $\mathrm{n}(\%)$ & $22(21.4)$ & $7(21.2)$ & $15(21.4)$ & 0.980 \\
\hline Bamboo spine & $24(23.3)$ & $8(24.2)$ & $16(22.9)$ & 0.877 \\
\hline Dorsal kyphosis & $21(20.4)$ & $7(21.2)$ & $14(20.0)$ & 0.887 \\
\hline Training, $\mathrm{n}(\%)$ & $25(24.3)$ & $7(21.2)$ & $18(25.7)$ & 0.619 \\
\hline Smoking, n (\%) & $15(14.6)$ & $3(9.1)$ & $12(17.1)$ & 0.280 \\
\hline
\end{tabular}

BASDAI = Bath Ankylosing Spondylitis Disease Activity Index; ESR = Erythrocyte sedimentation rate.

ical variables appropriately, and odds ratio (OR) and 95\% confidence interval (CI) were used for the assessment of risk factors. All $\mathrm{P}$ values were 2-tailed, and confidence intervals (CIs) were set at $95 \%$. p values less than 0.05 were considered as significant.

\section{Results}

Table 1 shows the demographic and clinical characteristics of AS patients according to the presence (carrier) or absence (non-carrier) of $M E F V$ mutations. Although so many clinic and demographic features (sex, age, age at disease onset, disease duration, BASDAI, Schober test, chest expansion, ESR, HLA-B27 status, family history of AS, Syndesmophtes, ocular involvement, hip involvement, cardiac involvement, articular pain, cervical pain, sakroiliitis, oral aphthous ulcers, bamboo spine, dorsal kyphosis, training, smoking) were analyzed, no significant differences were observed between patients with and those without $M E F V$ mutations.

In healthy controls group, mutation analysis showed that $19(15.8 \%)$ of the subjects were carrying one mutated $M E F V$ allele. The frequencies of M694V, M680I, V726A, E148Q and P369S mutation carriage were $4.2 \%$ (with $5 / 240$ allele frequency), $4.2 \%$ (5/240), $2.5 \%$ $(3 / 240), 4.2 \%(5 / 240)$ and $0.8 \%(1 / 240)$. respectively
(Table 2). Homozygous and compound heterozygous mutations were not detected in healthy controls. In patients group, mutation analysis showed that $33(32 \%)$ of the patients were carrying at least one mutated $M E F V$ allele (Table 2). No compound heterozygous but one homozygous mutation (M680I/M680I) was observed in patients group. The frequencies of M694V, M680I, V726A, E148Q and P369S mutation carriage in patients with AS were $10.7 \%$ (with 11/206 allele frequency), 6.8\% (8/206), $4.9 \%$ (5/2062), 8.7\% (9/206) and $1 \%(1 / 206)$, respectively. There was a statistically significant difference of the $M E F V$ gene mutation carrier rates between patients and controls groups $(p=0.004$, OR: 2.5, 95\% CI: 1.32-4.76) (Table 2). This association was also observed in allele frequencies $(p=0.005$, OR: 2.3 , 95\% CI: 1.27-4.2). When the $M E F V$ gene mutations were separately compared between patients and controls, any association couldn't be observed between these two groups. However, a relatively higher frequency was observed for M694V mutation in AS patients than controls $(10.7 \%$ versus $4.2 \%, p=0.060)$.

\section{Discussion}

In this study, we investigated the presence of genetic variants in the $M E F V$ gene, which encodes for pyrin (a putative regulator of inflammation activity and proIL- 
Table 2

Distribution of $M E F V$ variants in patients with AS compared with healthy controls

\begin{tabular}{|c|c|c|c|c|}
\hline & $\begin{array}{c}\text { AS patients } \\
(n=103)(\%)\end{array}$ & $\begin{array}{l}\text { Healthy subjects } \\
(n=120)(\%)\end{array}$ & $\mathrm{P}$ value & OR $(95 \% \mathrm{CI})$ \\
\hline \multicolumn{5}{|l|}{ No. heterozygous } \\
\hline M694V/WT & $11(10.7)$ & $5(4.2)$ & 0.060 & $2.8(0.92-8.20)$ \\
\hline M680I/WT & $6(5.8)$ & $5(4.2)$ & 0.569 & $1.4(0.42-4.81)$ \\
\hline V726A/WT & $5(4.9)$ & $3(2.5)$ & 0.560 & $2.0(0.38-13.09)$ \\
\hline E148Q/WT & $9(8.7)$ & $5(4.2)$ & 0.161 & $2.2(0.71-6.80)$ \\
\hline P369S/WT & $1(1.0)$ & $1(0.8)$ & - & - \\
\hline \multicolumn{5}{|c|}{ No. homozygous or compound heterozygous } \\
\hline M680I/M680I & $1(1.0)$ & - & - & - \\
\hline Total mutations (n) & $33(32.0)$ & $19(15.8)$ & 0.004 & $2.5(1.32-4.76)$ \\
\hline Total allelle frequency $(\mathrm{n})$ & $34 / 206$ & $19 / 240$ & 0.005 & $2.3(1.27-4.2)$ \\
\hline M694V allelle & $11 / 206$ & $5 / 240$ & 0.065 & $2.7(0.91-7.76)$ \\
\hline M680I allelle & $8 / 206$ & $5 / 240$ & 0.261 & $1.9(0.61-5.90)$ \\
\hline
\end{tabular}

$M E F V$ : Mediterranean Fever; AS = ankylosing spondylitis; WT: wild type. The results that are statistically significant are shown in boldface.

$1 \beta$ processing), in a cohort of Turkish patients with a clinical diagnosis of AS. In the present study, we found a statistically significant increased prevalence of $M E F V$ variants in AS patients in comparison with healthy controls. Four independent groups of investigators from Turkey recently reported their studies on $M E F V$ variations in patients with AS [23-26]. The first study, from Central Anatolia, showed an increased frequency of eight $M E F V$ variations (M694V [c.2080A $>$ G, p.Met 694Val], V726A [c.2177T >C, p.Val726Ala], E148Q [c.442G >C, p.Glu148GIn], M680I [c.2040G $>$ C, p. Met680Ile], M694I [c.2082G >A, p.Met694Ile], P369S [c.1105C > T, p.Pro369Ser], F479L [c.1437C > G, p.Phe 479Leu], and R761H [c.2282G $>$ A, p.Arg761His]) in 95 patients with AS, without any clinical correlation [23]. The second study, from the Central Black Sea region, did not find any significant difference between 80 AS patients and 85 controls in terms of twelve common $M E F V$ gene mutation (E148Q, P369S, F479L, M680I (G/C), M680I (G/A), I692del [c.2074_2076del, p.Ile692delIle], M694V, M694I, K695R [c.2084A>G, p.Lys695Arg], V726A, A744S [c.2230G >T, p.Ala744 Ser], and $\mathrm{R} 761 \mathrm{H}$ ) frequencies [24]. Because the statistical analysis were based on all $M E F V$ gene mutations taken together in the study of Durmus et al., a significantly higher frequency of M694V in the AS patients was escaped from the notice of them (OR: 3.9, 95\% CI $1.03-14.75, P<0.045)$ [27]. In the third study, it was shown that the allele frequency of $M E F V$ variants (M694V, V726A, E148Q, M680I, P760P, K695R) in $62 \mathrm{AS}$ patients was significantly higher than that in the pooled control group of 50 healthy controls plus 46 rheumatoid arthritis (RA) patients from the Aegean region of Turkey $(15.3 \%$ versus $6.8 \% ; P=$
0.021). M694V was significantly more common in the AS group than in the combined control groups $(P=$ 0.008 ) [25]. In the fourth study from the Marmara region of Turkey, it was revealed that $M E F V$ variations (M694V, M680I, V726A and E148Q) were significantly more frequent in 193 patients with AS (22.3\%) compared with 103 healthy control subjects $(9.7 \%$, OR: 2.67, 95\% CI: 1.28-5.56). This difference was more prominent for exon 10 variations (M694V, V726A, M680I) (OR 3.75, 95\% CI 1.41-9.97), especially for the most-penetrant variation M694V ( $p=0.006$, OR $4.73,95 \%$ CI 1.39-16.12) [26]. The results of these four studies from different Turkish populations are concordant with our study. These studies can be accepted as confirmation of the association of the penetrant $M E F V$ variations with AS in independent groups of patients from Turkey. However, although we found a relatively high frequency of M694V mutation in patients with AS, we could not reach the statistical significant as the other researchers found.

There was no significant difference between $M E F V$ mutation carriers and non-carriers with respect to the clinical and demographic characteristics which was also shown in the previous studies $[23,25]$. However, Durmus et al. found significant differences between the carrier and non-carrier groups regarding BASFI, BASDAI, hip involvement and ESR [24]. In another study, $M E F V$ variations were more frequent in HLA-B27negative patients with AS, and the difference was statistically significant in patients carrying exon 10 variants (M694V, M680I, V726A) [26].

In conclusion, this study reveals evidence suggesting that $M E F V$ variations are associated with AS. However, this and other studies have low statistical power because 
of their small sample size and the low frequency of $M E F V$ variants. Further studies with larger populations will be required to confirm these findings suggesting an association of M694V with AS and to clarify its influence on the disease course. Molecular analysis of MEFV gene in AS patients should be important in order to offer a genetic counseling.

\section{Acknowledgments}

This study was supported by the Gaziosmanpasa University (Project No: 2011/54).

\section{References}

[1] Onen F, Akar S, Birlik M, Sari I, Khan MA, Gurler O, Ergor A, Manisali M, Akkoc N. Prevalence of ankylosing spondyloarthritis and related spondyloarthritides in an urban area of Izmir, Turkey. J Rheumatol 2008; 35: 305-9.

[2] Cakır N, Pamuk ON, DervişE, Imeryüz N, Uslu H, Benian O, Elelçi E, Erdem G, Sarvan FO, Senocak M. The prevalences of some rheumatic diseases in western Turkey: Havsa study. Rheumatol Int 2011; 32(4): 895-908.

[3] The International FMF Consortium. Ancient missense mutations in a new member of the RoRet gene family are likely to cause familial Mediterranean fever. Cell 1997; 90: 797-807.

[4] Langevitz P, Livneh A, Zemer D, Shemer J, Pras M. Seronegative spondyloarthropathy in familial Mediterranean fever. Semin Arthritis Rheum 1997; 27(2): 67-72.

[5] Kausik P, El-Sobkie NI, Sheab D, Malaviya AN. Familial mediterranean fever with HLAB27 positive ankylosing spondylitis in a young armenian man. Clin Exp Rheumatol 1999; 17: 387-8.

[6] Uthman I, Hajj-Ali RA, Arayssi T, Masri AF, Nasr F. Arthritis in familial Mediterranean fever. Rheumatol Int 2001; 20(4): $145-8$.

[7] Balaban B, Yasar E, Ozgul A, Dincer K, Kalyon TA. Sacroiliitis in familial Mediterranean fever and seronegative spondyloarthropathy: importance of diVerential diagnosis. Rheumatol Int 2005; 25(8): 641-4.

[8] Keles I, Aydin G, Tosun A, Inal E, Keles H, Orkun S. Familial Mediterranean fever and ankylosing spondylitis in a patient with juvenile idiopathic arthritis: a case report and review of the literature. Rheumatol Int 2006; 26(9): 846-51.

[9] Duman I, Balaban B, Tugcu I, Dincer K. Familial mediterranean fever unusually coexisted in an ankylosing spondylitis patient. MEFV mutation has any role? Rheumatol Int 2007; 27(7): 689-90

[10] Sari I, Simsek I, Guvenc I, Sanal HT, Erdem H, Pay S, Dinc A. Osteopoikilosis coexistent with ankylosing spondylitis and familial Mediterranean fever. Rheumatol Int. 2009; 29(3): 3213.

[11] Booth DR, Gillmore JD, Lachmann HJ, Booth SE, Bybee A, Soytürk M, Akar S, Pepys MB, Tunca M, Hawkins PN. The genetic basis of autosomal dominant familial Mediterranean fever. QJM 2000; 93(4): 217-21.
[12] ShinarY, Livneh A,VillaY, Pinhasov A, Zeitoun I, Kogan A, Achiron A. Common mutations in the Mediterranean fever gene associated with rapid progression to disability in nonAshkenazi Jewish multiple sclerosis patients. Genes Immun 2003; 4: 197-203.

[13] Rabinovich E, Livneh A, Langevitz P, Brezniak N, Shinar E, Pras M, Shinar Y. Severe disease in patients with rheumatoid arthritis carrying a mutation in the Mediterranean fever gene. Ann Rheum Dis 2005; 64: 1009-14.

[14] Giaglis S, Mimidis K, Papadopoulos V, Thomopoulos K, Sidiropoulos P, Rafail S, Nikolopoulou V, Fragouli E, Kartalis G, Tzioufas A, Boumpas D, Ritis K. Increased frequency of mutations in the gene responsible for familial Mediterranean fever (MEFV) in a cohort of patients with ulcerative colitis: evidence for a potential disease-modifying effect. Dig Dis Sci 2006; 51: 687-92.

[15] Rabinovich E, Shinar Y, Leiba M, Ehrenfeld M, Langevitz P, Livneh A. Common FMF alleles may predispose to development of Behcet's disease with increased risk for venous thrombosis. Scand J Rheumatol 2007; 36: 48-52.

[16] Canete JD, Arostegui JI, Queiro R, Gratacós J, Hernández MV, Larrosa M, Alperí M, Moll C, Rius J, Sanmartí R, Yagüe J. An unexpectedly high frequency of MEFV mutations in patients with anti - citrullinated protein antibody - negative palindromic rheumatism. Arthritis Rheum 2007; 56: 2784-8.

[17] Pras E, Aksentijevich I, Gruberg L, Balow JE Jr, Prosen L, Dean M, Steinberg AD, Pras M, Kastner DL. Mapping of a gene causing familial Mediterranean fever to the short arm of chromosome 16. N Engl J Med 1992; 326: 1509-13.

[18] Ting JP, Kastner DL, Hoffman HM. CATERPILLERs, pyrin and hereditary immunological disorders. Nat Rev Immunol 2006; 6: 183-95.

[19] Papin S, Cuenin S, Agostini L, Martinon F, Werner S, Beer HD, Grütter C, Grütter M, Tschopp J. The SPRY domain of Pyrin, mutated in familial Mediterranean fever patients, interacts with inflammasome components and inhibits proIL1beta processing. Cell Death Differ 2007; 14: 1457-66.

[20] Van der Linden S, Valkenburg HA, Cats A. Evaluation of diagnostic criteria for ankylosing spondylitis: a proposal for modification of the New York criteria. Arthritis Rheum 1984; 27: 361-8.

[21] Gershoni-Baruch R, Kepten I, Shinawi M, Brik R. Direct detection of common mutations in the familial Mediterranean fever gene (MEFV) using naturally occuring and primer mediated restriction fragment analysis. Hum Mutat 1998; 14: $91-4$.

[22] Aksentijevich I, Torosyan Y, Samuels J, Centola M, Pras E, Chae JJ, Oddoux C, Wood G, Azzaro MP, Palumbo G, Giustolisi R, Pras M, Ostrer H, Kastner DL. Mutation and haplotype studies of familial Mediterranean fever reveal new ancestral relationships and evidence for a high carrier frequency with reduced penetrance in the Ashkenazi Jewish population. Am J Hum Genet 1999; 64(4): 949-62.

[23] Cinar M, Dinc A, Simsek I, Erdem H, Koc B, Pay S, Tunca Y, Kilic S, Gul D. The rate and significance of Mediterranean fever gene mutations in patients with ankylosing spondylitis: a three-month, longitudinal clinical study. Rheumatol Int 2008; 29: $37-42$.

[24] Durmus D, Alayli G, Cengiz K, Yigit S, Canturk F, Bagci $\mathrm{H}$. Clinical significance of MEFV mutations in ankylosing spondylitis. Joint Bone Spine 2009; 76(3): 260-4.

[25] Akkoc N, Sari I, Akar S, Binicier O, Thomas MG, Weale ME, Birlik M, Savran Y, Onen F, Bradman N, Plaster CA. Increased prevalence of M694V in patients with ankylosing spondylitis: 
additional evidence for a link with a familial Mediterranean fever. Arthritis Rheum 2010; 62: 3059-63.

[26] Cosan F, Ustek D, Oku B, Duymaz-Tozkir J, Cakiris A, Abaci N, Ocal L, Aral O, Gül A. Association of familial Mediterranean fever-related MEFV variations with ankylosing spondylitis. Arthritis Rheum 2010; 62(11): 3232-6.

[27] Akkoc N, Gul A. Comment on the article by Durmus, et al. Clinical significance of MEFV mutations in ankylosing spondylitis [letter]. Joint Bone Spine 2010; 77: 281. 


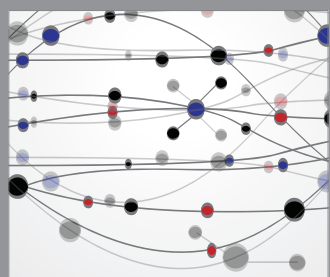

The Scientific World Journal
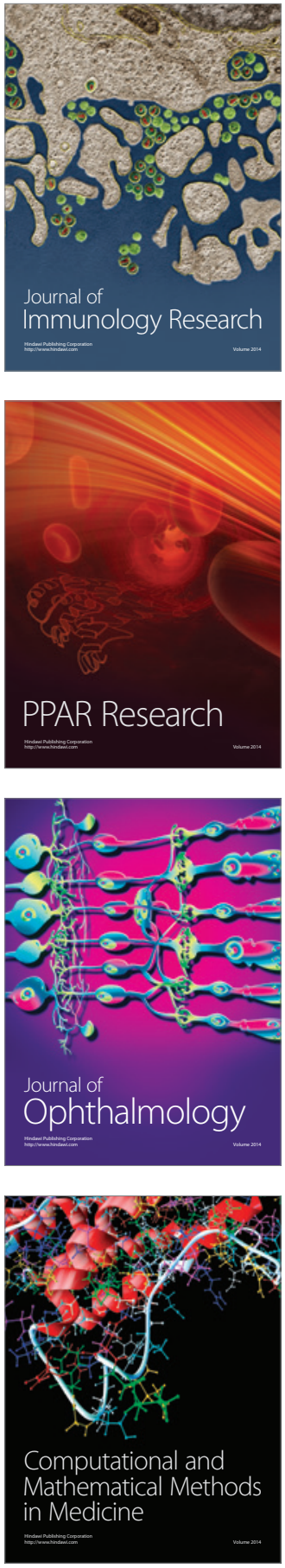

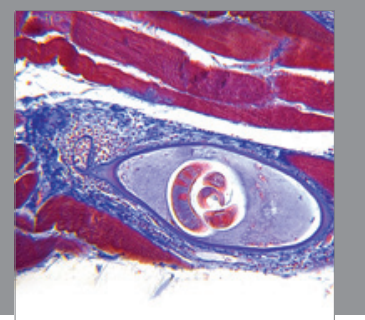

Gastroenterology

Research and Practice
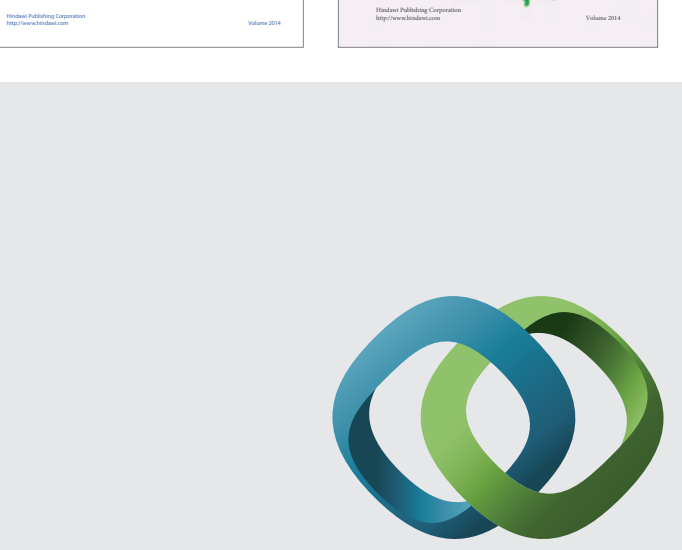

\section{Hindawi}

Submit your manuscripts at

http://www.hindawi.com
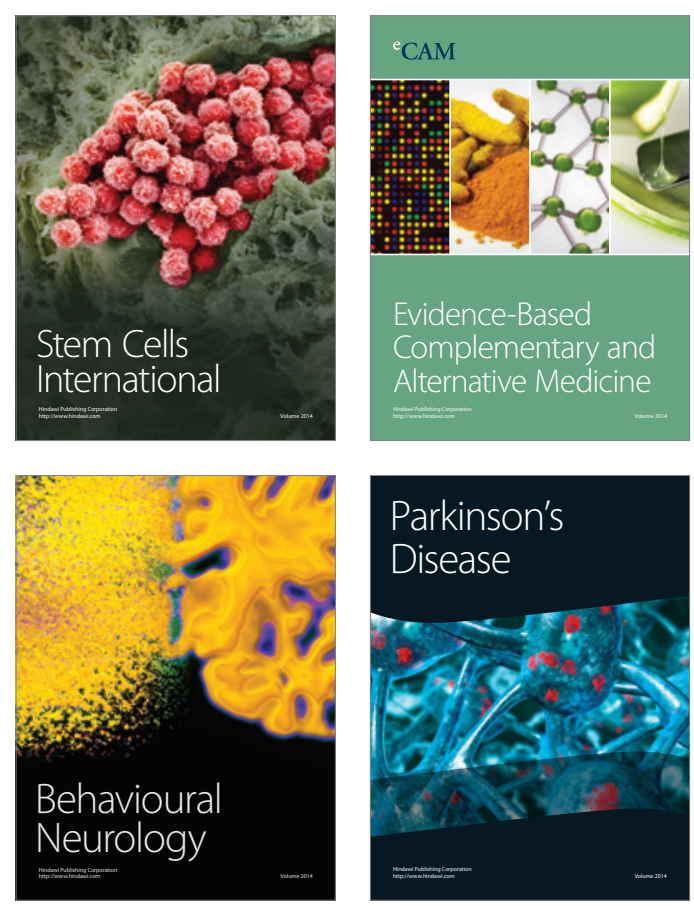

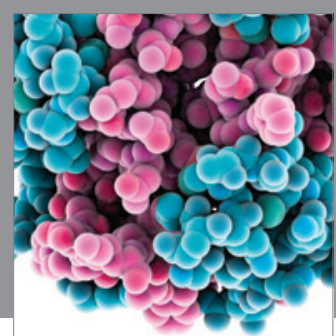

Journal of
Diabetes Research

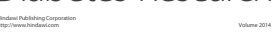

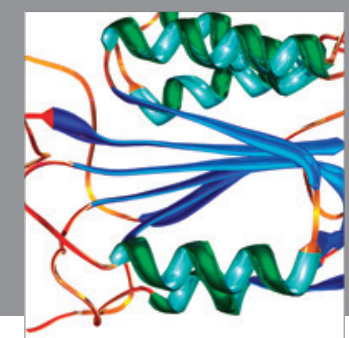

Disease Markers
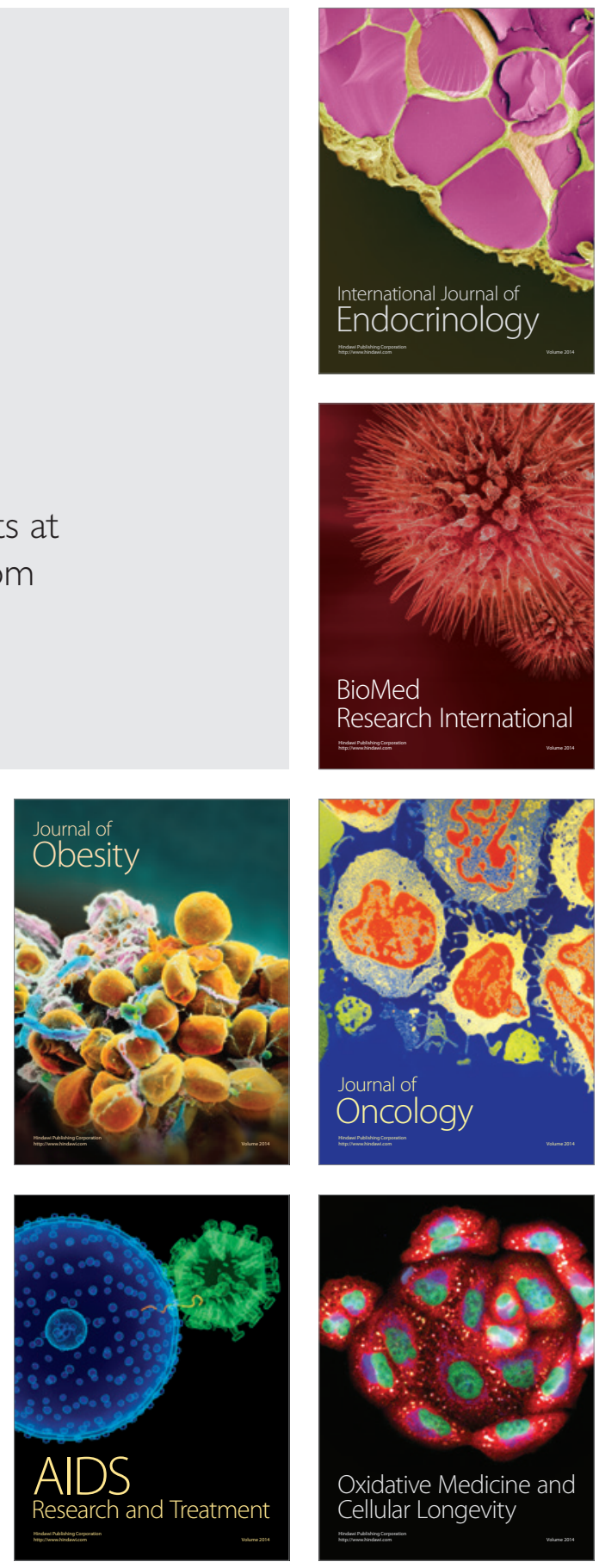